\title{
Apolipoprotein E Antibodies Affect the Retention of Passive Avoidance Memory in the Chick
}

\author{
Chris Lancashire, ${ }^{\dagger}$ Radmila Mileusnic and Steven P.R. Rose \\ Brain and Behaviour Research Group, The Open University, Milton Keynes MK7 6AA, UK
}

\section{SUMMARY}

Isoforms of apolipoprotein $E$ (ApoE) have been implicated as risk factors in Alzheimer's disease. We have, therefore, examined the possible role of ApoE in memory formation, using a one-trial passive avoidance task in dayold chicks. Birds were trained on the task and then at various times pre or post-training were injected intracerebrally with anti-ApoE. Immunofluorescence staining demonstrated the presence of the antibody bound to the neuropil, close to the injection site and adjacent to the ventricle, with a residence time in the brain of up to $30 \mathrm{~min}$. Chicks that were injected $30 \mathrm{~min}$ pre-training or just post-training with $5 \mu \mathrm{g} /$ hemisphere of the antibody learned the task, but were amnesic when tested at $30 \mathrm{~min}$ or at subsequent times up to $24 \mathrm{hr}$ post-training. When tested at $24 \mathrm{hr}$, birds injected $5.5 \mathrm{hr}$ posttraining showed unimpaired retention. Birds injected with $5 \mu \mathrm{g} / \mathrm{hemisphere}$ of anti-ApoA-I (which has a brain distribution similar to that of anti-ApoE) at 30 min pretraining showed no amnesia, indicating the specificity of the effect to the ApoE. Possible mechanisms for this effect are discussed.

\section{KEYWORDS}

amnesia, learning, Alzheimer's disease, ApoA-I

\footnotetext{
${ }^{\dagger}$ Corresponding author

Tel: +0044-(0)-1908-652125

Fax: +0044-(0)-1908-654167

e-mail: c.l.lancashire@open.ac.uk
}

\section{INTRODUCTION}

Apolipoprotein E (ApoE) is a low-molecularweight, 299 amino-acid protein, with a molecular size variously described as ranging from $34-37 \mathrm{kDa}$ (Beffert et al., 1998; Puttfarken et al., 1997; Stone et al., 1997). ApoE is involved in cholesterol and phospholipid transport and metabolism, mediating lipid uptake by cells by acting as a ligand for the neuronal and astrocytic receptors for low density lipoprotein (LDL) and very low density lipoprotein (VLDL), among others. The LDL and VLDL receptors bind and internalize ApoE-containing lipoproteins, and the complex is then degraded (for review see Beffert et al., 1998). ApoE mRNA is richly present in the brain; ApoE is synthesized notably by astrocytes (Poirier et al., 1991). In mammals, ApoE is one of eight exchangeable and soluble lipoproteins (including ApoA I, II, IV and ApoC-I, II, III; Babin et al., 1997). Until recently, the Apo-E form was believed to be absent from other non-mammalian vertebrate species; Babin et al., (1997) have shown, however, that the ApoE gene is not confined to mammals but is also present in other vertebrates, being highly expressed, for instance, along with ApoA-I in zebra fish during development.

ApoE exists in a number of isoforms, ApoE2, ApoE3, and ApoE4. Although their exact function is unclear, either in normal or in pathological metabolism, apolipoproteins have recently been implicated as potential risk factors in Alzheimer's disease (AD), with the $A P O E 4$ allele increasing and the $A P O E 2$ and $A P O E 3$ alleles decreasing the risk of early onset of the disease (Strittmatter \& Roses, 1996). Just why this association should be the case is not known, although ApoE has been described as interacting with the Alzheimer's-associated amyloid 
precursor protein (APP) by way of a common receptor, the LDL-receptor-related protein (Kounnas et al., 1995). ApoE also interacts, presumably following internalization, with tau and other cytoskeletal proteins (Fleming et al., 1996). Such interactions might imply that ApoE could play a role during aging by helping to stabilize dendritic arborizations or synaptic junctions. ApoE has been shown to be neurotrophic, increasing neurite length in culture, as well as ameliorating $\beta$-amyloidinduced toxicity (Puttfarcken, 1997).

As one of the early characteristics of progressive $\mathrm{AD}$ is memory dysfunction, notably an inability to transfer new information into longer-term memory, exploring the possible role of ApoE in memory formation is relevant. Some groups have claimed that Apo-E-deficient mice show cognitive impairments (Masliah et al., 1997), although such impairment may depend on genetic background. Other groups (Anderson et al., 1998) did not find major behavioral consequences of the deletion.

Following Hebb (1949), long-term memory is generally believed to be stored in the brain in the form of altered patterns of neuronal connectivity. Modifying these patterns requires the remodeling of synapses by changing their number, dimensions, or morphology (Rose, 1995). The biochemical cascade required for such remodeling has been studied in a variety of vertebrate species and training tasks. Convergent evidence from several laboratories has identified a sequence of events which, beginning with synaptic transients, second messenger release, and the activation of transcription factors and immediate early genes, culminates in the synthesis and insertion into pre- and post-synaptic membranes of a variety of glycoprotein cell-adhesion molecules (Rose, 1996).

A model system in which this cascade has been mapped in detail is the one-trial, passive avoidance learning task in day-old chicks. In this task, birds are offered a small bright bead, at which they will peck spontaneously within a few seconds. If the bead is coated in a bitter tasting substance they will peck once, evince a disgust response, and avoid similar but dry beads subsequently (Andrew, 1991). The merit of the one-trial task is that it is quick, reproducible, and sharply timed, and further, that the soft, unossified skull of the chick enables agents that putatively might either enhance or inhibit memory formation to be directly injected into the brain within a few seconds, without anesthesia or overt behavioral distress.

We have identified [for references see Rose (1995, 1996)] a sequence of biochemical changes occurring in a specific region of the chick forebrain, the intermediate medial hyperstriatum ventrale (IMHV), in the minutes to hours following pecking at the bitter bead. The changes include, within minutes of training, the release of glutamate, upregulation of NMDA glutamate receptors, opening of presynaptic calcium channels, and altered phosphorylation of the presynaptic protein B50 (GAP 43). One hr after training, expression of the protein product of the immediate early gene $c-f o s$ is enhanced, which is then followed 4-8 hr post-training by enhanced protein synthesis, posttranslational glycosylation, and transport to the synaptic membranes of several species of cell adhesion molecules, including the neural cell adhesion molecule NCAM and L1 (NgCAM). Blockade of any step in this sequence results in the onset of amnesia for the task, as a result of which chicks peck at rather than avoid the bitter bead on test. Thus, antagonists of the NMDA receptor, of presynaptic calcium channels, or of inhibitors of the nitric oxide synthase enzyme, injected either just before or just after training, produce an early onset of amnesia and are presumed to prevent activation of later steps in the cascade.

Antibodies to specific synaptic membrane proteins, such as NCAM and L1, which can bind to the external domains of these molecules, also produce a time-dependent amnesia for the task. Anti-NCAM produces amnesia only if injected during a late phase in the cascade, $5.5 \mathrm{hr}$ posttraining, whereas anti- $\mathrm{L} 1$ is amnestic at two time windows, whether injected $30 \mathrm{~min}$ before training or $5.5 \mathrm{hr}$ post-training (Scholey et al., 1993, 1995). We suggested that this late phase is a period that is associated with the transition from short-term to long-term memory (Rose, 1995).

Granted the extracellular location of the apolipoproteins and their interaction with membrane-bound receptors, a logical approach to inquiring whether 
they have a specific role to play in the cascade would be, therefore, to examine the effect of antibodies to such molecules on learning and memory for the passive avoidance task. In this paper we report that antibodies to ApoE, but not to ApoA-I, when injected around the time of training, are indeed amnestic.

\section{EXPERIMENTAL}

\section{Animals and training}

Commercially obtained Ross Chunky eggs were incubated and hatched in our own brooders and held until $24 \pm 6 \mathrm{hr}$ old. The chicks were then placed in pairs in small aluminum pens, pretrained, and trained essentially as described by Lossner \& Rose (1983). Briefly, following an equilibration period of $1 \mathrm{hr}$, chicks were pretrained by three 10 -sec presentations of a small (2-mm diameter) white bead, at approximately $5 \mathrm{~min}$ intervals. Chicks failing to peck at the bead at least twice in three presentations $(<5 \%)$ were not used subsequently, but remained in their pens for the duration of the experiment. Following the last pretraining trial, the chicks were injected, where appropriate, as described below, before being trained by a $10 \mathrm{sec}$. presentation of a 4-mm-diameter chrome bead that had been dipped in the bitter-tasting methylanthranilate. At various times after training, the chicks were tested by offering them a small (2-mm-diameter) white bead, followed $10 \mathrm{~min}$ later by a dry 4-mm-diameter chrome bead, each for 20-30 sec. The chicks were considered to remember the task if they pecked at the white bead but avoided the chrome bead at test, and to have forgotten the task if they pecked at both beads. Only chicks pecking at the bitter bead on training and on the white bead at test were included in the final results. Among the chicks meeting the criterion ( $>80 \%)$, recall was calculated as a percent avoidance score (that is, the percentage of chicks in each group that avoided the chrome bead). Each chick was trained and tested only once, and the differences between the groups were tested for statistical significance using the $\chi^{2}$ test. The significance levels were set at $5 \%$.

\section{Antibodies and injections}

Antibodies to ApoE and ApoA-I were purchased from Boehringer Mannheim (East Sussex, UK) and from Calbiochem-Novabiochem (Nottingham, UK) respectively. Anti-ApoE is a murine monoclonal antibody (mAb) prepared against human apolipoprotein E; anti-ApoA-I is a polyclonal antibody raised in rabbits; both antibodies belong to the IgG class. Each antibody preparation was diluted appropriately with saline for injection. Bilateral injections of antibody or saline control $(5 \mu l)$ were made using a 10- $\mu$ l Hamilton syringe fitted with a plastic sleeve to allow a penetration of $3.5 \mathrm{~mm}$. The correct placement of injections into the IMHV was ensured by using a custom-built headholder (Davis et al., 1979), and the injections were routinely visually monitored post-mortem. The injections are rapid ( $<30 \mathrm{sec}$ per bird) and cause no observable distress to the chicks. Normally, one chick of a pair in each pen was injected with the antibody and the other with saline. The animals were injected and tested by an experimenter who was blind regarding which treatment each chick had received.

\section{Western blotting technique}

Synaptic plasma membrane (SPM) proteins were prepared as described by Murakami et al. (1986), separated by SDS-PAGE under reducing conditions using a $12 \%$ polyacrylamide gel (Laemmli, 1970), and then transferred to nitrocellulose (Burnette, 1981). The blots were routinely checked by post-transfer staining with Ponceau S. The nitrocellulose was incubated in blocking buffer [Tris-buffered saline (TBS) pH 7.5 containing 5\% skimmed milk powder and $0.05 \%$ Tween 20]. The antibodies were diluted in blocking buffer (ApoE $30 \mu \mathrm{g} / \mathrm{ml}$, ApoA-I $20 \mu \mathrm{g} / \mathrm{ml}$ ), and the blot was incubated overnight at $4^{\circ} \mathrm{C}$. After three $10 \mathrm{~min}$ washes, peroxidase-conjugated anti-mouse IgG (for ApoE) and peroxidase-conjugated anti-rabbit IgG (for ApoA-I) were added at a dilution of 1:500 in blocking buffer, and the blot was incubated overnight at $4^{\circ} \mathrm{C}$. The immuno-reactive bands were detected as described previously (Scholey et al., 1993). To check the specificity of the anti-ApoE, 


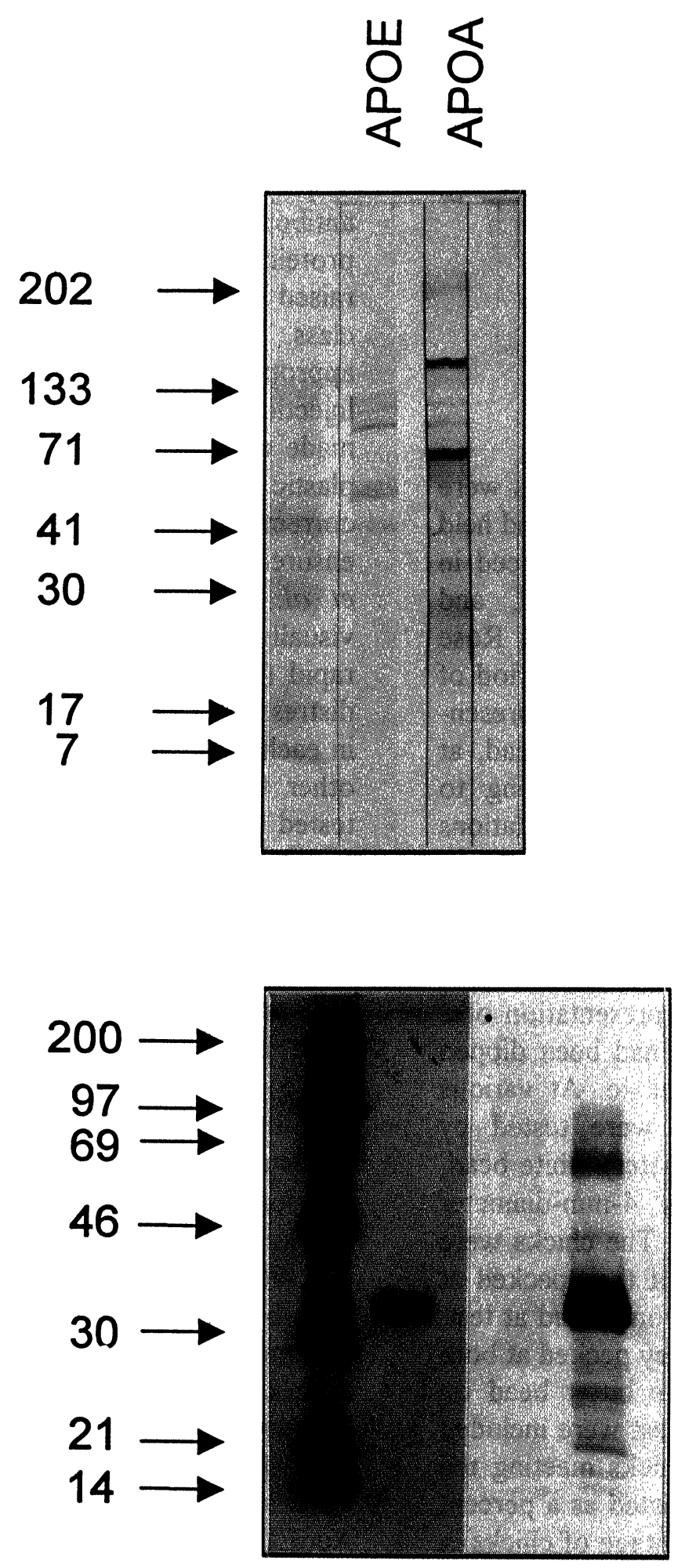

Fig. 1:(a) Immunoreactivity of ApoE and Apo-A-I antibodies with SPM proteins. SDS-PAGE and Western immunoblotting were performed as described in the Experimental section. Each track contained $50 \mu \mathrm{g}$ of SPM protein from day-old chicken forebrain. Lane 1: Rainbow standard; Lane 2: anti-ApoE (30 $\mu \mathrm{g} / \mathrm{ml})$; Lane 3: anti-ApoA-I $(20 \mu \mathrm{g} / \mathrm{ml})$. (b) SDS-PAGE and Western blot of authentic human Apo-E. Lane 1: Rainbow standard; Lane 2: SDS-PAGE of $3 \mu \mathrm{g}$ of authentic human ApoE; Lane 3: Western blot of ApoE with monoclonal anti-human Apo-E antibodies ( $2.5 \mu \mathrm{g} / \mathrm{ml})$. 
$3 \mu \mathrm{g}$ of human ApoE (Human Plasma, VLDL Calbiochem-Novabiochem) was electrophoresed on $12 \%$ SDS-PAGE, and a Western blot was performed as above, using anti-ApoE at $2.5 \mu \mathrm{g} / \mathrm{ml}$.

\section{Immunocytochemistry}

ApoE and ApoA-I antibodies $(5 \mu \mathrm{g}$ each in a total volume of $5 \mu \mathrm{l}$ ) were injected bilaterally into the IMHV as described above. The chicks were killed 10,30 , or $60 \mathrm{~min}$ later and the forebrains were removed, frozen slowly in pre-cooled isopentane, and stored at $-40^{\circ} \mathrm{C}$. Cryostat sections (15 microns) were collected at $-18^{\circ} \mathrm{C}$ onto Super Frost Gold Plus slides (Merck, Dorset, UK), air dried for $30 \mathrm{~min}$ at room temperature, and then stored at $-40^{\circ} \mathrm{C}$ until processed. The sections were equilibrated to room temperature, fixed for $8 \mathrm{~min}$ with cold paraformaldehyde (4\%) in TBS (pH 7.5), washed once with TBS for $5 \mathrm{~min}$, and then probed with the secondary antibody diluted in TBS (pH 7.5 or $\mathrm{pH} 9.0$ ), containing $0.1 \%$ Nonidet $\mathrm{P} 40$ and $2 \%$ bovine serum albumin (Sigma-Aldrich, Dorset, UK). Texas Red-conjugated anti-mouse IgG (Vector Labs, Peterborough, UK) diluted 1:75 at $\mathrm{pH} 9$ was used to locate the injected anti-ApoE, and fluorescein-conjugated anti-rabbit IgG (Sigma) diluted $1: 50$ at $\mathrm{pH} 7.5$ to locate the anti-ApoA-I. After fixation and washing, the slides were drained, and $50 \mu 1$ of anti-ApoE probing antibody was applied per section. The sections were incubated for $1.5 \mathrm{hr}$ in a moist box at room temperature and then washed three times for $5 \mathrm{~min}$ with TBS. After the slides were drained, $50 \mu \mathrm{l}$ anti-ApoA-I probing antibody was applied per section, and the above procedure was repeated. After the final wash, the sections were preserved using a fluorescent antifade mountant (Dako, High Wycombe, UK). To check that the injections were correctly placed, sections adjacent to those probed using fluorescence were fixed and washed as above, stained with $0.25 \%$ aqueous toluidine blue, dehydrated by passing through ethanol (80\%-100\%), cleared in xylene, and then mounted in DPX (Raymond Lamb). The sections were examined on a Zeiss Axiophot $(\times 25)$ or a Leica confocal microscope $(\times 100)$.

\section{RESULTS}

\section{Characterization of antibodies}

To determine the pattern of SPM proteins isolated from chick brain that were recognized by $\mathrm{mAb}$ anti-human ApoE and polyclonal anti-ApoA-I, the gels were overloaded with $50 \mu \mathrm{g}$ of SPM. Figure 1a shows the Western blots obtained when chick SPMs were probed with antibodies to ApoE and ApoA-I. Anti-ApoE gave a relatively weak signal, recognizing bands running at $41,50,72,90$, and $110 \mathrm{kD}$. Anti-ApoA-I gave a much stronger signal, recognizing two major bands with relative molecular masses of 60 and $140 \mathrm{kD}$, as well as a number of minor bands, two (at 71 and $90 \mathrm{kD}$ ) corresponding to those for ApoE. Figure 1b shows the SDS gel pattern obtained from $3 \mu \mathrm{g}$ of human $\mathrm{ApoE}$, and the corresponding Western blot when probed with the mAb to human ApoE. Although the ApoE showed only one major band on the gel, at around $34 \mathrm{kD}$, the corresponding blot showed multiple bands; the major band was very diffuse, as is characteristic of glycosylated proteins, and overlapped with the $41 \mathrm{kD}$ band found in chick SPMs; approximate correspondences with the 50 and $71 \mathrm{kD}$ bands were also seen.

\section{Recognition and residence time of antibody in the chick forebrain}

To determine the pattern of antibody binding in the chick IMHV, and the residence time therein, chicks were injected into the IMHV bilaterally with a solution containing $5 \mu \mathrm{g}$ of each antibody per hemisphere, and then killed either $10 \mathrm{~min}, 30 \mathrm{~min}$, or $60 \mathrm{~min}$ after the injection. The brains were frozen and prepared for immunocytchemistry. Figure 2 is a montage showing the distribution of immunofluorescence $10 \mathrm{~min}$ after injection of the antibodies. The photographs show a concentration of immunofluorescence around the injection site in the IMHV (Fig. 2, a,b), in what appears to be 'trails' through the neuropil (Fig. 2, c,d) and around the ventricle (Fig. 2, e,f). Note also (Fig. 2, g) the very circumscribed region of damage around the 

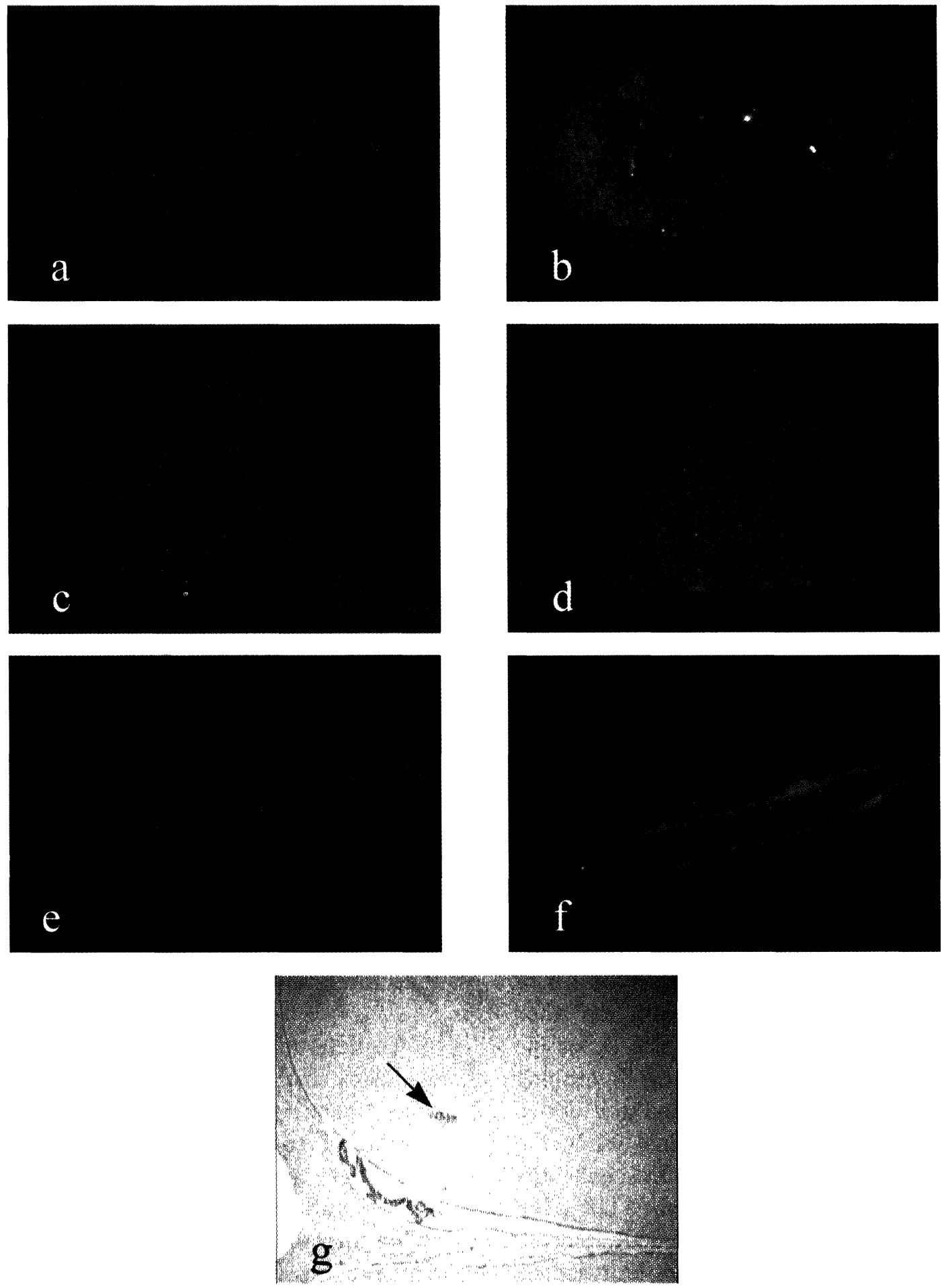

Fig. 2: Immunocytochemistry of anti-ApoE and anti-Apo-A-I localization at 10 min post-injection. One-day-old chicks were injected bilaterally into the IMHV with anti-ApoE (a,c,e) and anti-ApoA-I (b,d,f). Ten min later, the chicks were killed, brain tissue frozen, and immunocytochemistry carried out on $15 \mu \mathrm{m}$ coronal sections as described in the Experimental section. Texas Red conjugated anti-mouse IgG was used to locate the injected anti-ApoE and Fluorescein-conjugated antirabbit IgG to locate the anti-ApoA. Sections (a-f) were examined on a Leica confocal microscope (x100). Toluidine blue counterstained sections (g) were examined on a Zeiss Axiophot (x25). Figures show coronal sections through the forebrain in the region of A 8.8 (Kuenzel \& Masson, 1988). Sections a-b: injection site; c-d: Neuropil; e-f: Ventricles; g: Toluidine blue counterstaining, arrow indicates the injection site. 

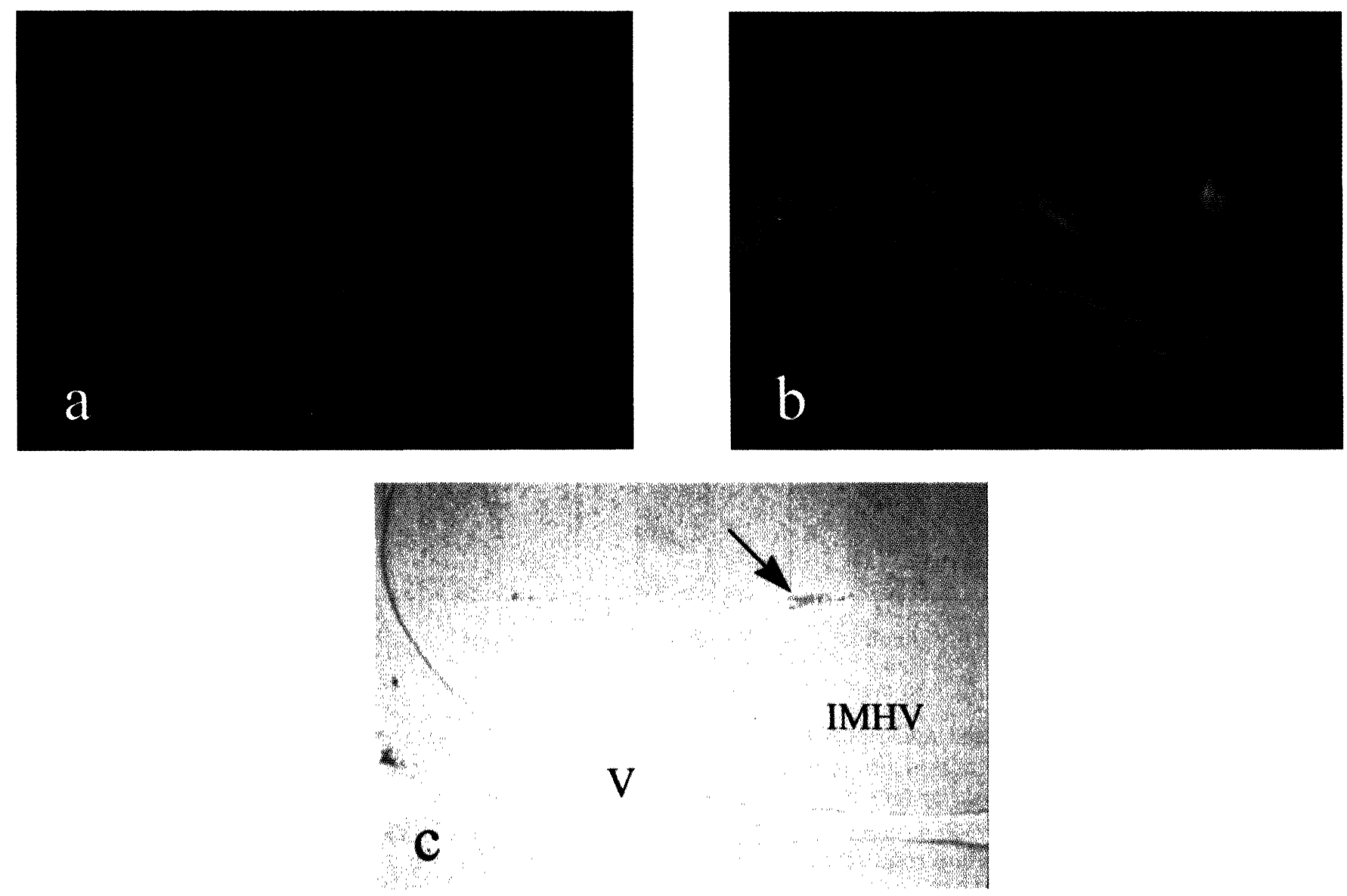

Fig. 3: Immunocytochemistry of anti-ApoE and anti-Apo-A-I localization $30 \mathrm{~min}$ post- injection. One-day old chicks were injected bilaterally into the IMHV with anti-ApoE (a) and anti-ApoA-I (b). Thirty min later chicks were killed, brain tissue frozen and immunocytochemistry carried out on $15 \mu \mathrm{m}$ coronal sections as described in the Experimental section. Texas Red conjugated anti-mouse IgG was used to locate the injected anti-ApoE and Fluorescein-conjugated anti-rabbit IgG to locate the anti-ApoA. Sections (a-b) were examined on a Leica confocal microscope (x100). Toluidine blue counterstained sections (c) were examined on a Zeiss Axiophot $(\times 25)$. Sections a-b show the remaining fluorescence in ventricles; $c$ : Toluidine blue counterstaining, the arrow indicates the injection site. V- ventricle, IMHV- intermediate medial hyperstriatum ventrale.

injection site. The two antibodies were remarkably similar in the distribution of immunofluorescence, suggesting that both recognized antigens located next to plasma membranes or in extracellular material in the IMHV. The residence time (or at least activity) was relatively brief, however; as Fig. 3 shows; by $30 \mathrm{~min}$ after the injection, the fluorescence had migrated to the ventricles and was barely visible. At $1 \mathrm{hr}$ post-training (data not shown), no fluorescence could be detected. Thus, the time window for the putative biological activity was short.

The effects of antibodies on learning and memory for the passive avoidance task

Initial studies (data not shown) had indicated that the chicks could tolerate injection loads of up to $10 \mu \mathrm{g} /$ hemisphere of anti ApoE without suffering overt physiological or behavioral stress. As Fig. 4 


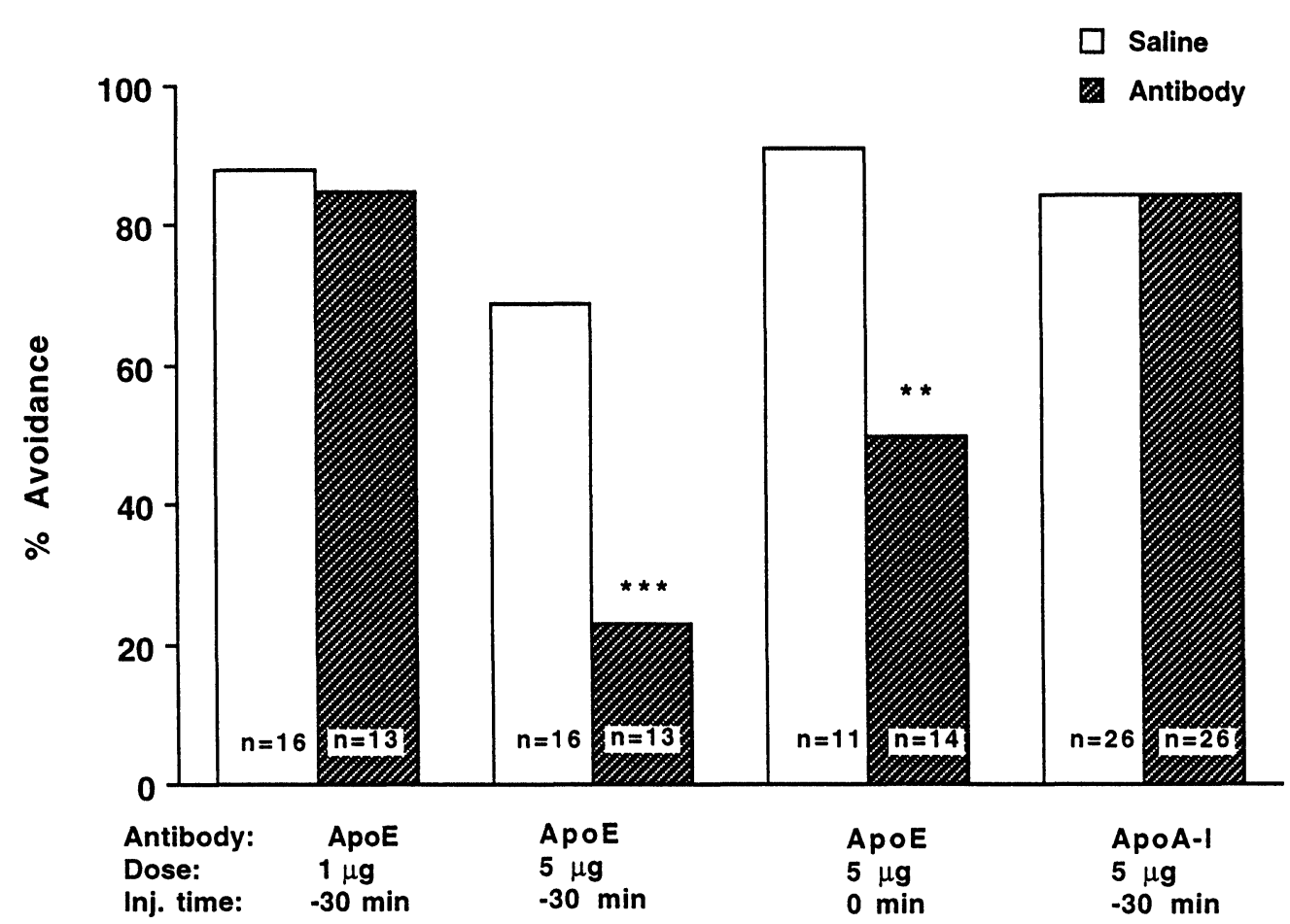

Fig. 4:The effects of anti-Apo-E and anti-ApoA-I on training retention. Chicks were trained and tested as described in the Experimental section. At 30 min pretraining or just post-training, chicks were injected bilaterally with saline or with antiApoE (1 or $5 \mu \mathrm{g} / \mathrm{hemisphere),} \mathrm{or} \mathrm{anti-ApoA-I} \mathrm{(} 5 \mu \mathrm{g} / \mathrm{hemisphere),} \mathrm{and} \mathrm{then} \mathrm{were} \mathrm{tested} \mathrm{for} \mathrm{retention} 24 \mathrm{hr}$ post-training. The number of chicks in each group is shown in columns. Injections of $5 \mu \mathrm{g} / \mathrm{hemisphere}$ anti-ApoE, either $30 \mathrm{~min}$ pretraining or just post-training, resulted in amnesia when analyzed by $\chi^{2}\left(30\right.$ min pretraining, $\chi^{2}=5.65, p<0.025$; just post- training, $\chi^{2}=4.67, p<0.05$ ).

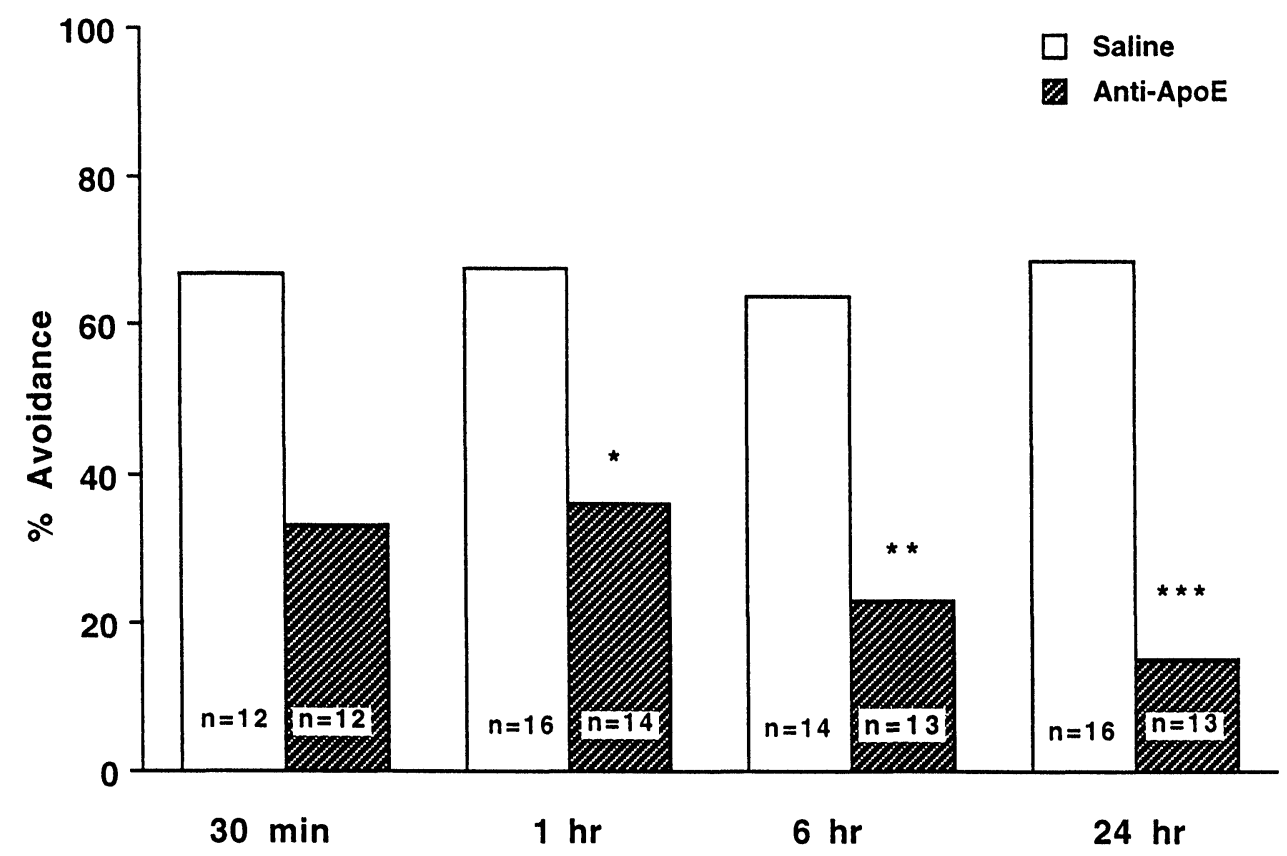

Fig. 5: Time of onset of amnesia for a passive avoidance task in chicks injected with anti-ApoE. Chicks were pretrained, trained, and injected with either saline or anti-ApoE $(5 \mu \mathrm{g} / \mathrm{hemisphere)} 30 \mathrm{~min}$ pretraining, as described in the Experimental section. Different groups of chicks were tested for retention at various times post-training. (each chick was trained and tested only once). The number of chicks in each group is shown in columns. 30 min post-training, $\chi^{2}=2.68, p<0.1 ; 1 \mathrm{hr}$ post-training, $\chi^{2}=3.35, \mathrm{p}<0.05 ; 6 \mathrm{hr}$ post-training, $\chi^{2}=4.70, \mathrm{p}<0.05 ; 24 \mathrm{hr}$ post-training, $\chi^{2}=8.12, \mathrm{p}<0.005$ ). 
shows, chicks injected with $5 \mu \mathrm{g}$, but not $1 \mu \mathrm{g}$, antiApoE per hemisphere 30 minutes before training showed significant amnesia when tested $24 \mathrm{hr}$ later. The amnesia was also apparent if the antibody was injected just post-training.

As Fig. 4 also shows, no amnesia occurred if, instead of anti-ApoE, the same concentration $(5 \mu \mathrm{g} /$ hemisphere) of anti-ApoA-I was injected. Amnesia did not occur in chicks injected with anti-ApoE 5.5 $\mathrm{hr}$ post-training (retention with saline controls: $70 \%, \mathrm{n}=14$; retention in antibody-injected chicks: $70 \%, n=14, n s)$. The amnesia was of rapid onset; chicks injected with $5 \mu \mathrm{g} / \mathrm{hemisphere}$ of anti-ApoE $30 \mathrm{~min}$ before training were amnesic when subsequently tested at 1,6 , or $24 \mathrm{hr}$. Although the degree of amnesia at $30 \mathrm{~min}$ did not quite reach a level of significance, the overall trend itself is clear (Fig. 5): The amnesia was of rapid onset and irreversible. The antibody did not, however, affect the behavior, visual capacity, or motor coordination of the birds during the training trials, as indicated by the finding that of the chicks injected with saline pretraining, 53/54 trained successfully; of those injected with anti-ApoE, 55/59 trained successfully.

\section{DISCUSSION}

Because ApoE isoforms have been implicated as risk factors for Alzheimer's disease, and the early stages of that disease are characterized by loss of the ability to transfer items from short-term to longterm memory, it has become of importance to assess the putative role of $\mathrm{ApoE}$ in that transfer process. One way of approaching this question is by examining the effect of gene deletions of ApoE, or of the specific isoform (ApoE 4), known to be a major risk factor for the disease (Strittmatter \& Roses, 1996).

Whereas one group (Masliah et al., 1997) reported cognitive impairment in mice with Apo-E deletions, others have found relative slight effects (Anderson et al., 1998). Such differences may be related to genetic background or to other factors affecting the interpretation of all such deletion experiments, notably the confounding effect of developmental and neuronal plasticity (Gerlai, 1996).

A more direct approach would be to attempt to interfere with the functioning of the protein during the actual processes of training and recall. One such method is provided by the use of antisense, an approach that we have employed previously in identifying a role for the protein product of the immediate early gene $c$-fos (Mileusnic et al., 1996) and for APP (Mileusnic et al., 1998). An unequivocal sequence for chick ApoE, however, has not yet been reported. An alternative is offered by the use of antibodies, which can be injected directly into the relevant brain region and can bind to either secreted proteins or the external domains of membrane-bound proteins. We have used such methods to identify time windows, during which antibodies to the cell adhesion molecules NCAM and L1 will cause amnesia for a passive avoidance task in the chick (Scholey et al., 1993, 1995; Tiunova et al., in press).

In rodents, similar methods have shown comparable results (Doyle et al., 1992; Fox et al., 1995; Alexinsky et al., 1997; Roullet et al., 1997). In particular, antibodies to L1 cause amnesia for the passive avoidance task if injected into the IMHV either $30 \mathrm{~min}$ pretraining or $5.5 \mathrm{hr}$ post-training, whereas antibodies to NCAM are amnestic only if injected during the second time window. We have argued that this finding indicates a role for the cell adhesion molecules in the transition from short-term to long-term memory.

ApoE, a low molecular weight protein that is secreted and binds to membrane receptors, meets the criteria for proteins whose function might be disrupted by the use of antibodies in this way; hence our decision to explore the effect of anti-ApoE in our chick learning model. Until relatively recently, although ApoA-I is known to be present in chicks, and indeed its sequence and expression have been studied in detail (Rajavashisth et al., 1987; Ferrari et al., 1987), ApoE was thought to be present only in mammals. As non-mammalian vertebrates have now been shown to express ApoE, however, especially during development (Babin et al., 1997), the way seemed open to explore the role of ApoE in the passive avoidance paradigm.

Western blotting showed that when authentic human VLDL ApoE was probed with the mAb antiApoE, a number of bands, in addition to the expected one at $34-37 \mathrm{kD}$, were recognized. The 
bands were not only very broad, making the precise molecular mass identification uncertain, but also showed the smearing that is characteristic of glycosylated proteins. Comparison with the blot obtained using chick SPMs showed a number of possible correspondences, including those found in the chick at 41,50 , and $71 \mathrm{kD}$ (Fig. 1, a,b). The chick SPM signal was weak, however, perhaps because much soluble ApoE had been removed during the preparation of the SPMs. By contrast, and not unexpectedly, antibody to ApoA-I gave a much stronger signal on Western blotting, with major bands seen at 60 and $140 \mathrm{kDa}$. The implication of the presence of multiple bands, even for the authentic human ApoE, is not known.

When injected into the IMHV, however, both antibodies showed strong immunofluor-escence, with no obvious differences in distribution and with extensive binding to the neuropil and around the ventricles in the minutes after injection (Fig. 2). The residence time of the antibodies was relatively brief; within $30 \mathrm{~min}$ post-injection most fluorescence was concentrated around the ventricles (Fig. 3), and had entirely disappeared by $60 \mathrm{~min}$. This result contrasts with the longer residence times found, for instance, for antibodies to NCAM (Scholey et al., 1993). The ventricular concentra-tion implies that much of the signal is lost by diffusion; some might be lost, however, because of internalization and inactivation of the antibody.

The apparent identity of the intracerebral distribution of the immunofluorescence of both antibodies points to a related functional distribution of their respective antigens, lending strength to the significance of the clear separation of effects on memory retention between the two. Anti-ApoA-I gave a stronger signal on Western blots of chick SPMs than did anti-ApoE, and had a similar distribution pattern upon injection into the IMHV. Anti-ApoE, however, and not anti-ApoA-I, was amnestic when injected into the IMHV either 30 min pre- or just post-training on the passive avoidance task. This result may be related to that of Masliah et al., (1997) who found that infusion of recombinant ApoE could alleviate some of the cognitive deficits that they observed resulting from the deletion of the gene for the protein. We can conclude that ApoE, while without effect on learning the avoidance task, is required for the task to be effectively remembered, even for a period as brief as $30 \mathrm{~min}$

The experiments described here point to a significant role for ApoE in the biochemical cascade that is associated with memory formation. That preand early post-training injections, but not those $5.5 \mathrm{hr}$ after training, resulted in amnesia suggests that this function is required at an early phase, rather than in the transition to long-term memory that we have postulated for NCAM and L1 (Rose, 1995, Scholey et al., 1995). As the possibility that the transport of LDL or VLDL is directly required for memory formation is not considered likely, at least not at this early time point, the implication would be that the effects of anti-ApoE are mediated via a blockade of some other function of the protein.

If, as we believe, memory formation requires the modulation of synaptic connectivity, the finding that ApoE affects neurite extension (Puttfarken et al., 1997) may be relevant. The most direct mechanism, however, may be via the interactions between ApoE and $\beta$-amyloid (Kounnas et al., 1995; Beffert et al., 1997). We have found that antibodies to APP, injected around the time of training, or antisense oligomers injected $12 \mathrm{hr}$ previously, are profoundly amnestic in the chick passive avoidance model (Mileusnic et al., 1998). The time course of onset of this amnesia parallels that found with the antiApoE. One implication is that the anti-APP amnesia occurs as a result of blocking the adhesion functions of the external domains of APP, which, like those of NCAM and L1, are necessary for synaptic remodeling. If $A p o E$ and APP interact via a membrane-bound lipoprotein receptor at the synapse, the amnestic effect of antibodies to ApoE could be explained. We are currently exploring these putative interactions and their effect on memory formation and retention.

\section{ACKNOWLEDGEMENTS}

We thank Dr Charles Large, of GlaxoWellcome, and members of the Brain and Behaviour Research Group for helpful discussions, Verina Waights for advice on the confocal microscopy, and 
Steve Walters and Dawn Sadler for care of the chicks. This work was supported by an MRCForesight LINK grant to SPRR.

\section{REFERENCES}

Alexinsky T, Przybyslawski J, Mileusnic R, Rose SPR, Sara SJ. Antibody to day- old chick brain glycoprotein produces amnesia in adult rats. Neurobiol Learn Mem 1997: 67, 14-20.

Anderson R, Barnes JC, Bliss TVP, Cain DP, Cambon K, Davies HA, et al. Behavioural, physiological, and morphological analysis of a line of apolipoprotein $\mathrm{E}$ knockout mouse. Neuroscience 1998; 85: 93-110.

Andrew RJ, ed, Neural and Behavioural Plasticity; The Use of the Domestic Chick as a Model. Oxford: University Press, 1991.

Babin PJ, Thisse C, Durliat M, Andre M, Akienko M-A, Thisse B. Both Apolipoprotein E and A-I genes are present in a non-mammalian vertebrate and are highly expressed during embryonic development. Proc Natl Acad Sci USA 1997; 94: 8622-8627.

Beffert U, Aumont N, Dea D, Lussier-Cacan S, Davignon J, Poirier J. $\beta$-amyloid peptides increase the binding and internalization of Apolipoprotein $E$ to hippocampal neurons. J Neurochem 1998; 70: 1458-1466.

Burnette WN. 'Western blotting' electrophoretic transfer of proteins from sodium dodecyl sulphate-polyacrylamide gels to unmodified nitrocellulose and radiographic detection with antibody and radioiodinated protein A. Anal Biochem 1981; 112: 195-203.

Davis JL, Masouka DT, Gerbrant LK, Cherkin A. Autoradiographic distribution of L-proline in chicks after intracerebral injection. Physiol Behav 1979; 22: 177-184.

Doyle E, Nolan PM, Bell R, Regan CM. Intraventricular infusions of anti-neural cell-adhesion molecules in a discrete posttraining period impair consolidation of a passive avoidance response in the rat. $\mathrm{J}$ Neurochem 1992; 59: 1570-1573.

Ferrari S, Tarugi P, Drusiani E, Calandra S, Fregni M. The complete sequence of chick Apolipoprotein AI mRNA and its expression in the developing chick. Gene 1987; 60: 39-46.

Fleming LM, Weisgraber KH, Strittmatter WJ, Troncoso JC, Johnson GVW. Differential binding of Apolipoprotein $\mathrm{E}$ isoforms to tau and other cytokeletal proteins. Exp Neurol 1996; 138, 252-260.

Fox GB, O'Connell AW, Murphy KJ, Regan CM. Memory consolidation induces a transient and timedependent increase in the frequency of neural cell adhesion molecule polysialylated cells in the adult rat hippocampus. J Neurochem 1995; 65: 2796-2799.
Gerlai R. Gene-targeting studies of mammalian behavior: is it the mutation or the background genotype? Trends Neurosci 1996; 19: 177-181.

Hebb DO. The Organization of Behavior. New York: Wiley, 1949.

Kuenzel WJ, Masson M. A Stereotaxic Atlas of the Brain of the Chick. Baltimore, MD: The Johns Hopkins University Press, 1988.

Kounnas MZ, Moir RD, Rebeck GW, Bush AI, Argraves WS, Tanzi RE, et al. LDL receptor-related protein, a multifunctional ApoE receptor, binds secreted betaamyloid precursor protein and mediates its degradation Cell 1995; 82: 331-340.

Laemmli UK. Cleavage of structural proteins during the assembly of the head of bacteriophage T4. Nature 1970; 227: 146-148.

Lossner B, Rose SPR. Passive avoidance training increases fucokinase activity in right forebrain base of day-old chicks. J Neurochem 1983; 41: 1357-1363.

Masliah E, Samuel W, Veinbergs I, Mallory M, Mante M, Saitoh T. Neurodegeneration and cognitive impairment in ApoE-deficient mice is ameliorated by infusion of recombinant ApoE. Brain Res 1997; 751: 307-314.

Mileusnic R, Anokhin K, Rose SPR. Antisense oligodeoxynucleotides to $c$-fos are amnestic for passive avoidance in the chick. NeuroReport 1996; 7: 12691272.

Mileusnic R, Lancashire C, Rose SPR. Involvement of $\beta$-APP in memory formation: antibody and antisense approach. Europ Neurosci Assn 1998; Abstr. 56.39.

Murakami K, Gordon-Weeks PR, Rose SPR. Isolation of post synaptic densities from day-old chicken brain. J Neurochem 1985; 46, 340-348.

Poirier J, Hess M, May PC, Finch CE. Astrocytic apolipoprotein E mRNA and GFAP mRNA in hippocampus after entorhinal cortex lesioning. Mol Brain Res 1991; 11: 97-106.

Puttfarken PS, Manelli AM, Falduto MT, Getz GS, LaDu MJ. Effect of apolipoprotein $E$ on neurite outgrowth and $\beta$-amyloid-induced toxicity in developing rat primary hippocampal cultures. J Neurochem 1997; 68: 760-769.

Rajavashisth TB, Dawson PA, Williams DL, Shackelford JE, Lebherz H, Lusis AJ. Structure, evolution and regulation of chicken apolipoprotein A-I. J Biol Chem 1987; 262: 7058-7065.

Rose SPR. Cell adhesion molecules, glucocorticoids and memory. Trends Neurosci 1995; 18: 502-506.

Rose SPR. Cell adhesion molecules and the transition from short- to long-term memory. J Physiol (Paris) 1996; 90: 387-391.

Roullet P, Mileusnic R, Rose SPR, Sara SJ. Neural cell adhesion molecules play a role in rat memory formation in appetitive as well as aversive tasks. NeuroReport 1997; 8: 1907-1911. 
Scholey AB, Mileusnic R, Schachner M, Rose SPR. A role for a chicken homolog of the neural cell adhesion molecule $\mathrm{L} 1$ in consolidation of memory for a passive avoidance task. Learn Mem 1995; 2: 17-25.

Scholey AB, Rose SPR, Zamani MR, Bock E, Schachner $M$. A role for the neural ccll adhesion molecule in a late consolidating phase of glycoprotein synthesis $6 \mathrm{hr}$ following passive avoidance training of the young chick. Neuroscience 1993; 55: 499-509.
Stone DJ, Rozovsky I, Morgan TE, Anderson CP, Hajian $\mathrm{H}$, Finch $\mathrm{CE}$. Astrocytes and microglia respond to estrogen with increased $A p o E$ mRNA in vivo and in vitro. Exp Neurol 1997; 143: 313-318.

Strittmatter WJ, Roses AD. Apolipoprotein E and Alzheimer's disease. Ann Rev Neurosci 1996; 19: 53-77.

Tiunova A, Anokhin KV, Schuchner M, Rose SPR. Three time windows for amnestic effect of antibodies to cell adhesion molecule L1 in chicks. NeuroReport 1998; 9:1645-1648. 

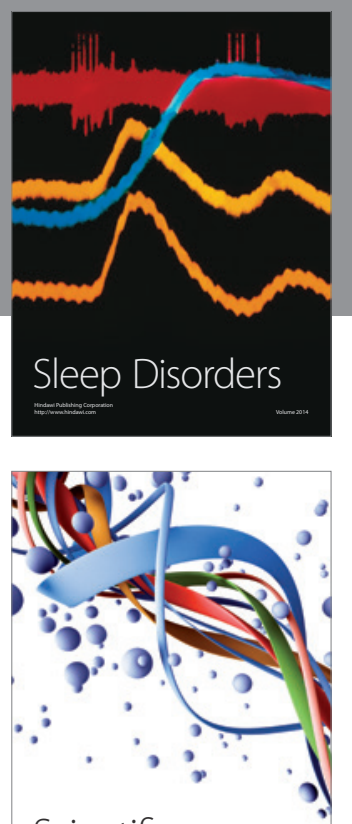

Scientifica
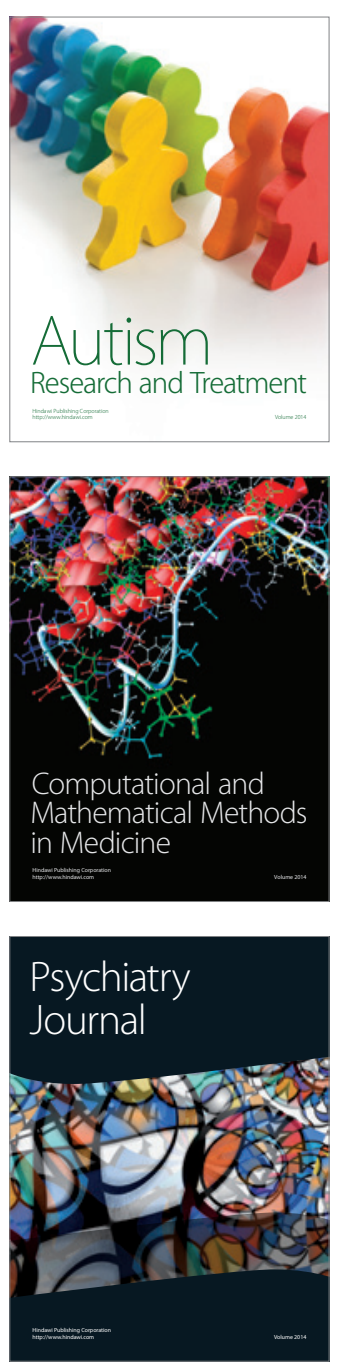
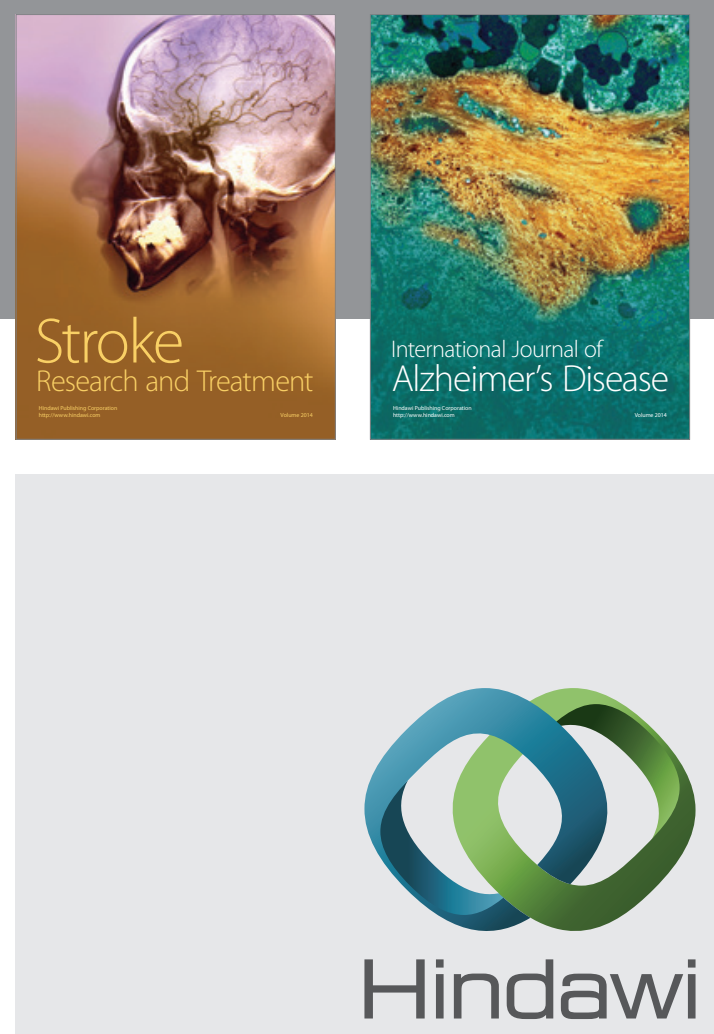

Submit your manuscripts at

http://www.hindawi.com
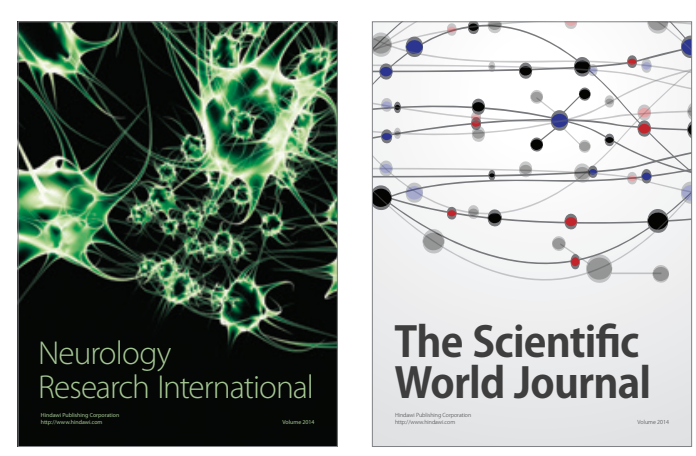

The Scientific World Journal

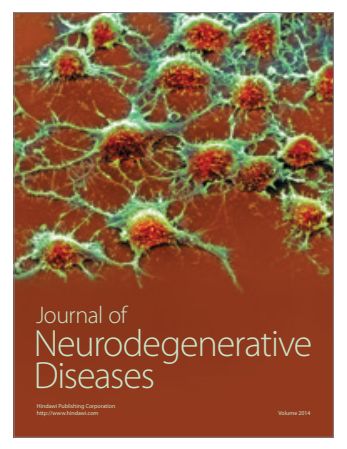

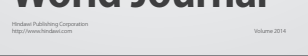

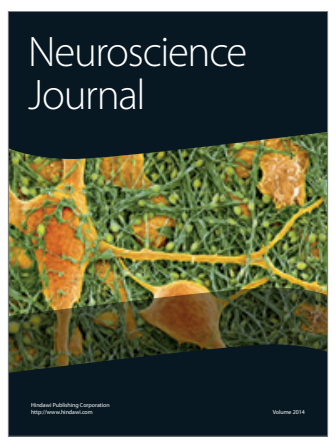

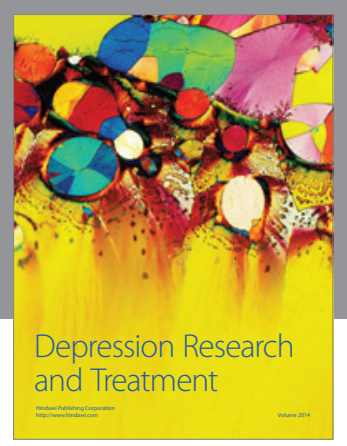
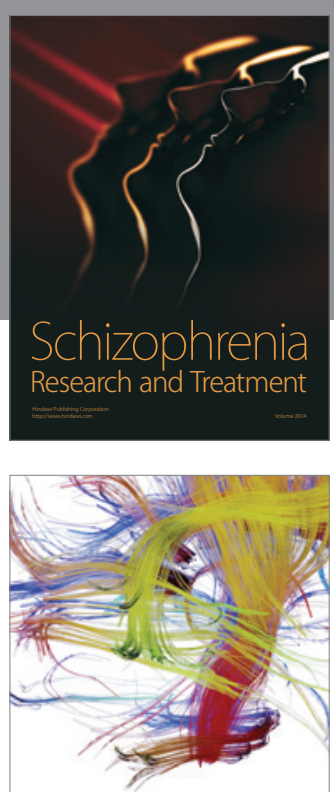

Brain Science

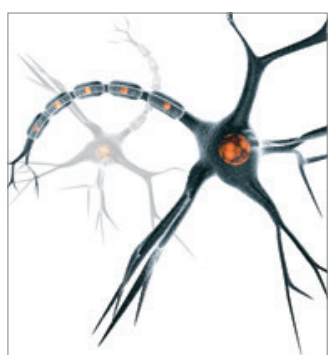

Neural Plasticity
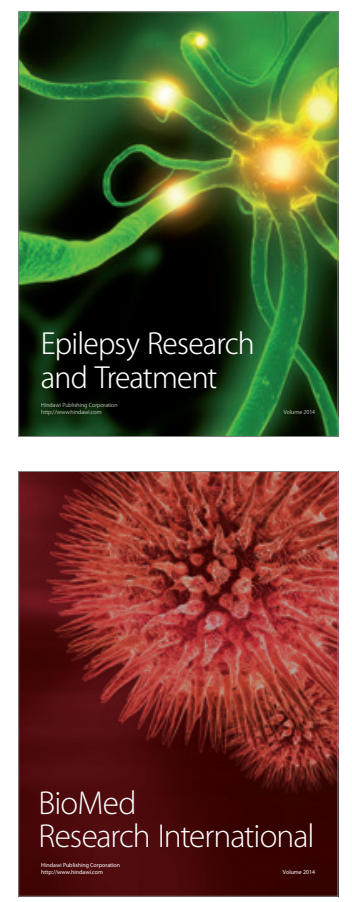

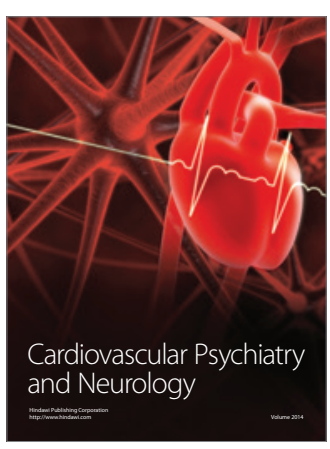

Parkinson's

Disease
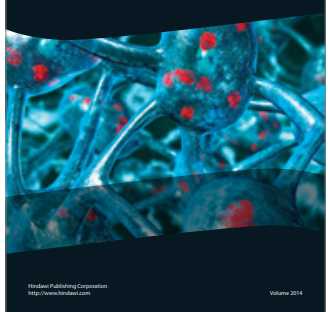